\title{
Chemical Plant Design for the Conversion of Plastic Waste to Liquid Fuel
}

\author{
Yusif Rhule Sam1,2, Lawrence Darkwah', Derrick Kpakpo Allotey1, Adjei Domfeh', \\ Mizpah Ama Dziedzorm Rockson ${ }^{1}$, Emmanuel Kwaku Baah-Ennumh1

\footnotetext{
${ }^{1}$ Department of Chemical Engineering, Kwame Nkrumah University of Science and Technology, Kumasi, Ghana

${ }^{2}$ Faculty of Engineering and Applied Sciences, University of Regina, Regina, Canada

Email: *mizpaha@yahoo.com
}

How to cite this paper: Sam, Y.R., Darkwah, L., Allotey, D.K., Domfeh, A., Rockson, M.A.D. and Baah-Ennumh, E.K. (2021) Chemical Plant Design for the Conversion of Plastic Waste to Liquid Fuel. Advances in Chemical Engineering and Science, 11, 239-249.

https://doi.org/10.4236/aces.2021.113015

Received: April 1, 2021

Accepted: June 28, 2021

Published: July 1, 2021

Copyright $\odot 2021$ by author(s) and Scientific Research Publishing Inc. This work is licensed under the Creative Commons Attribution International License (CC BY 4.0).

http://creativecommons.org/licenses/by/4.0/

\begin{abstract}
This paper presents the plant design for fuel production from plastic waste. The types of plastics to be used for the fuel production include polyethylene, polypropylene and polystyrene. All these materials are to be sourced from Kpone landfill site in Accra, Ghana, where the plant is to be situated. The major fuels produced are gasoline, diesel and kerosene with a plant capacity of approximately 1000 tons of plastic waste per day and its attainment is $95 \%$. The production process involves sorting the municipal solid waste to obtain suitable plastics. The plastics are extruded and cracked thermally in a Pyrolyzer and the gases from it are reformed over Zeolite-ZSM 5 as the catalyst in a reactor. Resulting vapours are fractionated in a column to obtain the various fuel components. The plant operates 24 hours/day and 347 days/year with 3 shifts per day of 8 hours per shift. Total capital required to build and start up the plant amounts to approximately 17 Million US Dollars. The plant life is 25 years with an annual rate of return of $34 \%$ and a payback period of 2.9 years for this project, after setting up. Annually, the plant would generate gross and net profits of approximately 9 Million US Dollars and 6.7 Million US Dollars respectively.
\end{abstract}

\section{Keywords}

Plastic Waste, Extrusion, Pyrolysis, Catalyst, Fuel, Techno-Economic Analysis

\section{Introduction}

As the world strives to develop, urbanization and industrialization have resulted in rapid increase in the amount of waste produced every year. Waste management has become a global concern as urban population rises. Among the kinds 
of solid wastes produced annually, over 300 million metric tons of these wastes are plastics [1]. The use of plastics for fabrication of various items of domestic and industrial purposes has increased over the years for reasons including; the durability and lightweight of plastics [2]. Additives such as stabilizers and anti-oxidants are added to the base materials of plastics to enhance their plastic properties. Improper disposal of plastic waste has a negative impact on the environment due to the presence of these stabilizers and anti-oxidants in plastics [3].

Recycling, landfilling and incineration are the well-known processes for managing plastic wastes [4]. In modern and developed societies, thermochemical conversion has been adopted to manage solid waste. Thermochemical conversion is also the safest technology available for converting plastic waste into energy. This method is characterised by the use of heat energy to transform plastic waste physically and chemically [5]. The renowned processes utilized under this technology are liquefaction, gasification and pyrolysis. Pyrolysis is the combustion of materials in the limited amount of oxygen. The main feedstock for plastics production is crude oil. Naphtha obtained from fractionating crude oil is subjected to catalytic cracking where hydrocarbons of smaller molecular weights are produced. These hydrocarbons include ethylene, propylene, butane and other hydrocarbons. These hydrocarbons are further refined to produce the base plastic materials. The refined hydrocarbons are processed together with additives to give the desired plastic properties [6].

Few types of plastics are suitable for producing clean fuel oil. Polyethylene, polypropylene and polystyrene contain mainly carbon and hydrogen. Moreover, their compounds have high heating values. These properties render these plastics suitable for the production of clean fuel oil. Polyvinyl Chloride (PVC) contains chlorine which is corrosive and hazardous for that process. Like PVC, Polyethylene terephthalate (PET) is commonly found in Municipal Solid Waste (MSW) streams. However, PET yields benzoic acid and terephthalic acid during pyrolysis. These properties render PET and PVC unsuitable for the pyrolysis process [7].

Methane, ethane, propane and butane are the main refinery gases from the pyrolysis of plastic wastes. The gases are by-products and because of their high energy content, they are used in the plant as fuel to provide heat energy for processes that require heating. Moreover, the gases serve as an alternative source of fuel to the plant, thus making the process cost-effective. Solid residue, char, can be produced in the pyrolysis process. However, this is highly dependent on the level of contaminants such as organic matter, sand, etc. that are attached to the feedstock [8]. One of the fuel products from plastic waste obtained by pyrolysis and further catalytic upgrading is the fuel oil. It is a mixture of $\mathrm{C}_{5}-\mathrm{C}_{30}$ hydrocarbons. The fuel oil obtained is further homogenized to produce kerosene, diesel and petrol.

Therefore, designing a chemical processing plant to produce liquid fuels i.e. diesel, gasoline, kerosene and residual fuel oil, from the plastic waste in the Kpone Landfill, is the main motivation for undertaking this project. The construction of 
the plant would contribute to the effective management and utilization of plastic waste at the Kpone landfill, Moreover, the quality of petrol and diesel produced from these suitable plastic wastes are of good quality as the regular fuel oil from crude oil refineries [8]. Hence, fuel oil from plastic wastes needs no additives to improve its functional properties. Moreover, fuel oil from plastics is free from contaminants such as lead and sulphur. This makes fuel from plastics cleaner [9].

This study provides a detailed techno-economic analysis that includes the description of the selected process, a Process Flow Diagram (PFD), a simulated 3D layout of the plant incorporating piping systems, detailed and systematic material and energy balances on each major equipment as well as the specification of the safety and pollution control measures as required [10]. The economic viability of the plant was also duly assessed using different economic indicators namely Rate of Return (ROR), Payback period, Discounted Cash Flow Rate of Return (DCFRR) to determine the feasibility of the plant [10]. A sensitivity analysis [11] was also carried out.

\section{Design Methodology}

A feasible process was selected from the various production processes obtained from the literature. The selected process was modified and the process flowsheet (PFS) for the plant was drawn using Microsoft Visio. The 3D model of the process flowsheet was designed using AutoCAD Plant $3 \mathrm{D}^{\circledR}$. The mass and energy balances for the entire process were performed on the major process units to quantify the amount of raw material, utilities, fuel required as well as products produced. Balances over individual process equipment specify the compositions and rate of process stream flows. The balances were carried in Microsoft Excel Worksheet. The design took into consideration the factors affecting safety of the plant, environment and employees to ensure the plant meets general safety standards and protocols outlined by the environmental and safety authorities. The plant location took into consideration the material safety and datasheet of the feedstock and products. This is to ensure the safety and efficacy of the plant and its neighbouring communities.

For the economic analysis, the total capital investment, which takes into account the physical plant cost (equipment cost, installation cost, etc.), indirect costs (supervision cost, contractor expenses, contingency fee) and working capital investment (revenue needed to kick start the production) was computed to determine the total investment needed for plant installation and start-up. The annual total production cost was also estimated as a sum of the manufacturing costs (raw material cost, labour costs, and heating/cooling utility cost, local taxes) and general expenses (distribution cost, administrative charges, research and development costs) [11].

Profitability analysis was conducted using the cumulative cash flow plot, ROR, pay-back period, DCFRR, break-even point. Sensitivity analysis was used to determine the financial feasibility of the plant. The ROR is computed as the ratio of 
the net annual profit to the total capital investment which serves as a simple index to evaluate the performance of the investment made. DCFRR considers the time value of money based on the amount of the investment that is unreturned at the end of each year during the estimated life of the project [10]. The breakeven point simply estimates the point in the lifetime of the plant where the cumulative annual profit becomes equal to the production costs as well as the quantity of the products (liquid fuel) produced at that time. The pay-back period is the number of years it takes to redeem the initial total investment [11].

\section{Analysis of the Process Plant}

\subsection{Process Description}

The process begins with sorting of the MSW. There are two manual sorting processes. The primary sorting section recovers the various components of the MSW while the secondary section recovers only plastics. After primary sorting, the residual waste is conveyed into the Trommel screen which recovers the fine particles from the coarse ones. The oversize waste materials from the rotary screen move onto the magnetic belt for separation of ferrous metals from nonferrous materials. Recovered plastics are conveyed onto the near-infrared (NIR) sorting machines to identify and sort plastics. Suitable plastics are then shredded for extrusion to be effective. The extruders have screws which rotate to effectively mix the molten plastics and eject it out into their respective pyrolyzers. Molten plastics from the extruders flow into the reactors. The reactors are equipped with agitators to enhance even heat distribution in the reactor. Each reactor has a screw auger conveyor for removing solid residues accumulated during the pyrolysis process. Fuel gases from the pyrolyzers are compressed and then flow into the catalytic reactors. These gases are further cracked and reformed in the catalytic reactors to commercial grade fuel gases which are later condensed and fractionated in a fractional distillation column. Liquid fuel from the distillation column is then cooled using heat exchangers and the cold gas is then stored. These processes are summarised in Figure 1 below. The simulated 3D layout for the processing plant is also shown in Figure 2 and Figure 3.

\subsection{Material Balance}

The plant is built to process 1000 tonnes per day of MSW. The plant attainment is $95 \%$ with all units operating 24 hours per day. The figures below show tabulated values that summarise material balance around each major equipment in the process plant. The flow rates used in the calculation and represented in table is in $\mathrm{kg} /$ day.

Figures 4-16 shows the material balances over individual major units for the processing plant.

\subsection{Energy Balance}

The energy balance on the plant is presented below with tabulated values of the 


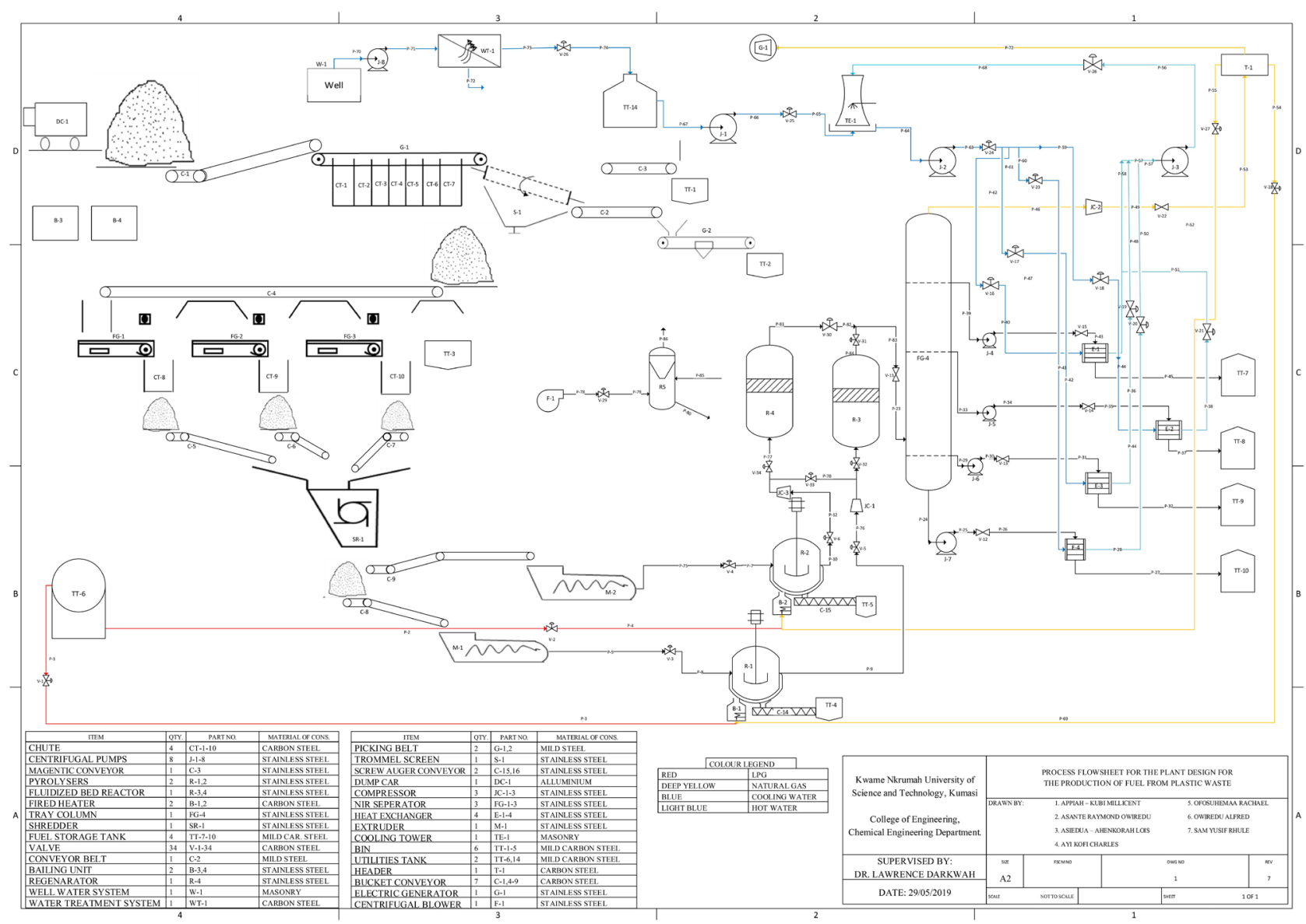

Figure 1. Process flowsheet of the processing plant.

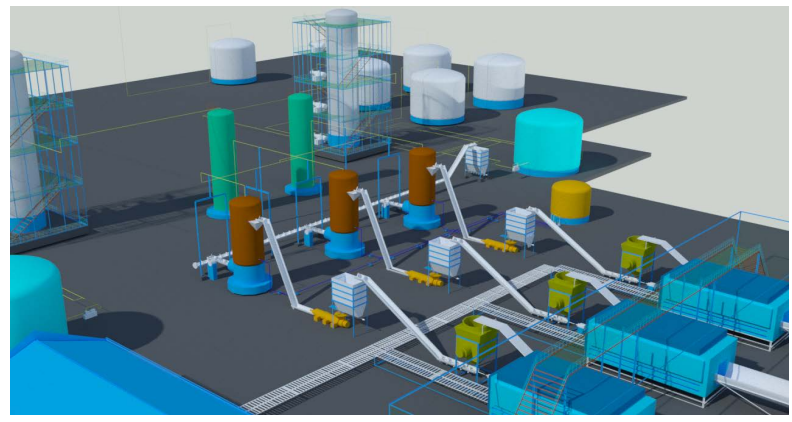

Figure 2. Simulated 3D design layout of the processing plant (View 1).

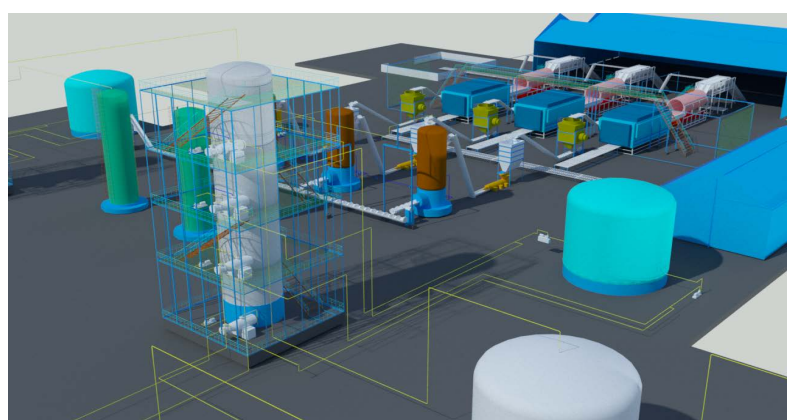

Figure 3. Simulated 3D design layout of the processing plant (View 2). 


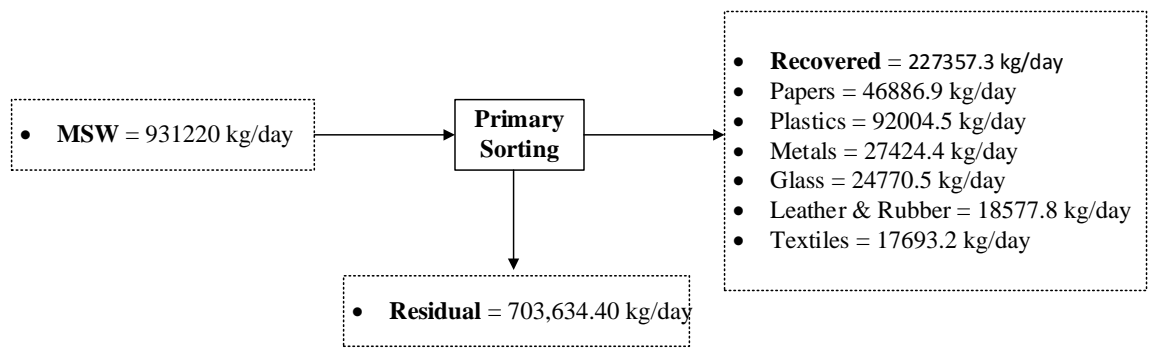

Figure 4. Material balance on primary manual sorting.

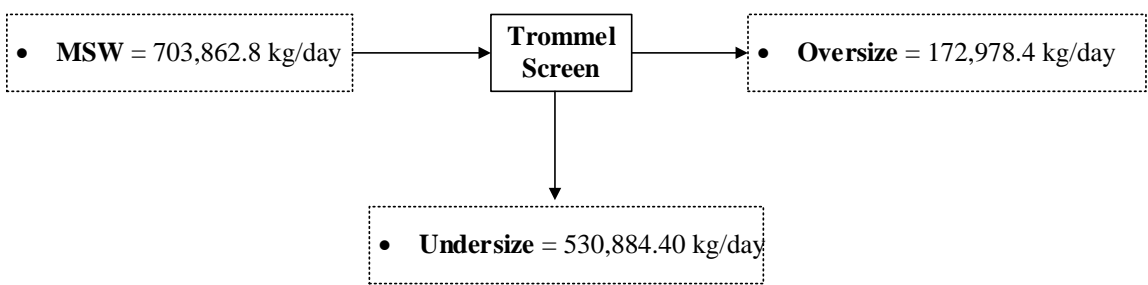

Figure 5. Material balance on trommel screen.

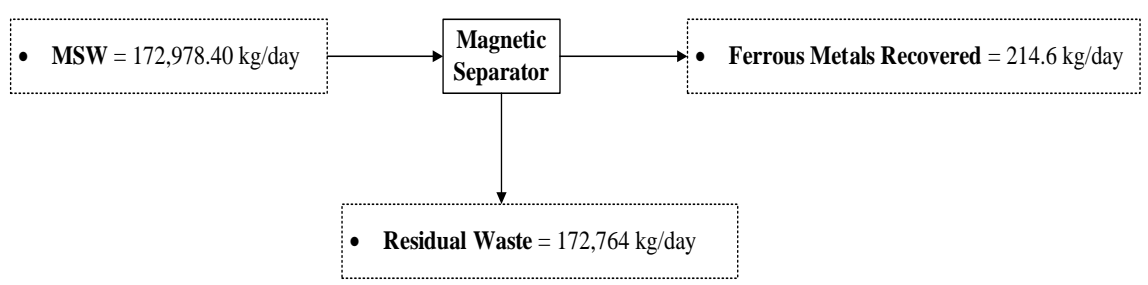

Figure 6. Material balance on magnetic separator.

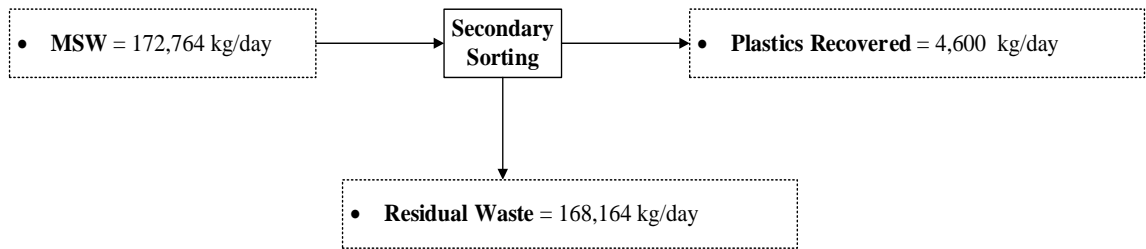

Figure 7. Material balance on secondary manual sorting.

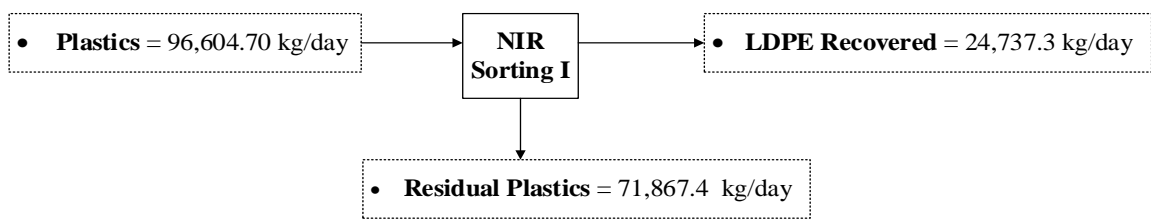

Figure 8. Material balance on LDPE NIR sorting.

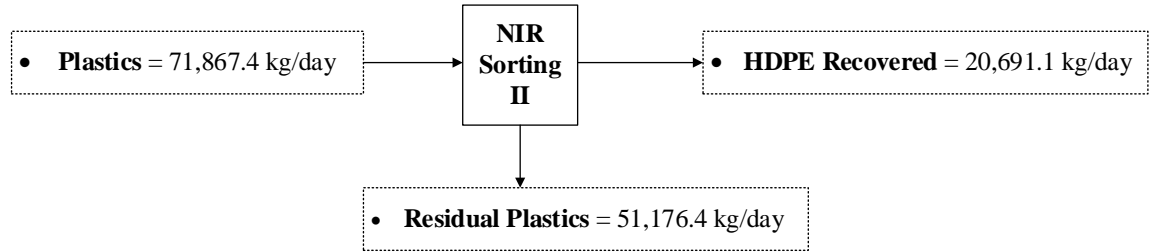

Figure 9. Material balance on HDPE NIR sorting. 


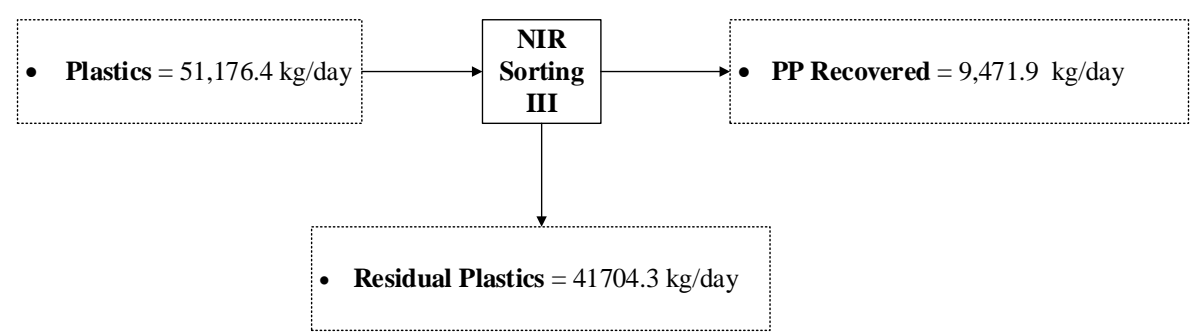

Figure 10. Material balance on PP NIR sorting.

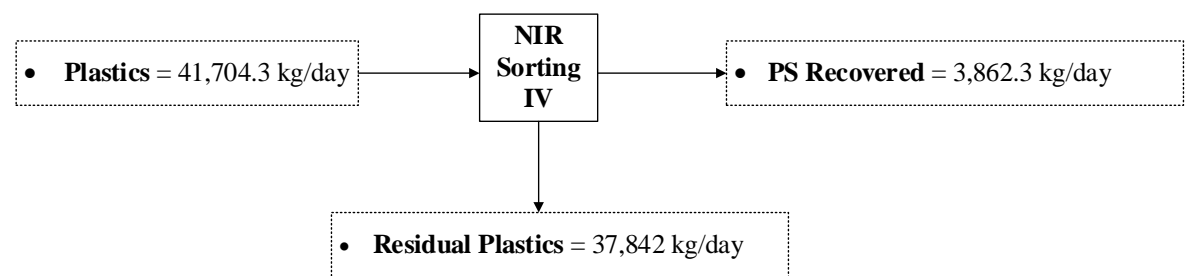

Figure 11. Material balance on PS NIR sorting.

- $\mathbf{L D P E}=24,737.3 \mathrm{~kg} / \mathrm{day}$

- HDPE $=20,691.1 \mathrm{~kg} / \mathrm{day}$

- $\quad \mathbf{P P}=9,471.9 \mathrm{~kg} / \mathrm{day}$

- $\quad$ PS $=3,862.3 \mathrm{~kg} / \mathrm{day}$

Figure 12. Material balance on extrusion.

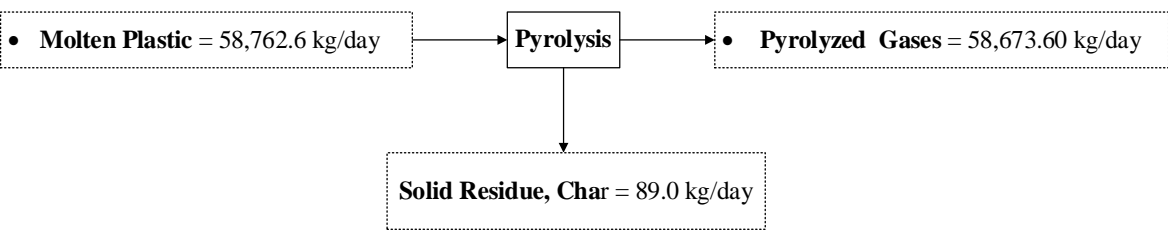

Figure 13. Material balance on pyrolysis.

$\bullet \quad$ Pyrolyzed Gases = 58,673.60 kg/day $\rightarrow \begin{aligned} & \text { Catalytic } \\ & \text { Cracking }\end{aligned} \longrightarrow \bullet \quad$ Reformed Gases = 58,673.60 kg/day

Figure 14. Material balance on catalytic cracking.

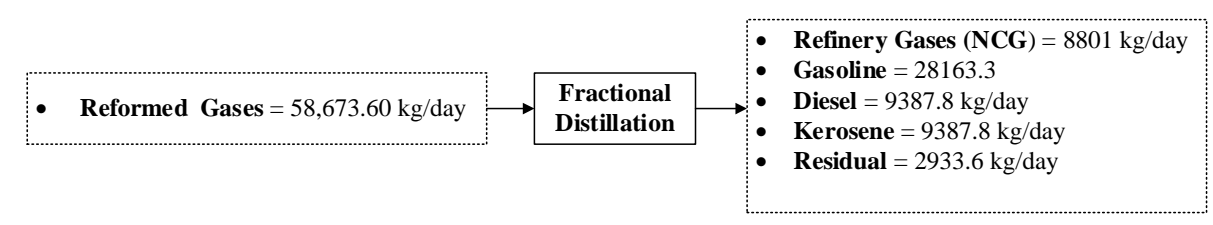

Figure 15. Material balance on fractional distillation.

enthalpies of components in all flow and streams. The reference temperature chosen was $25^{\circ} \mathrm{C}(298 \mathrm{~K})$ at which values of specific heat capacities were selected for calculations unless stated otherwise. The enthalpies are presented in $\mathrm{kJ} /$ day.

Figures 17-21 show the simplified version of energy balances over individual major units for the entire process. 


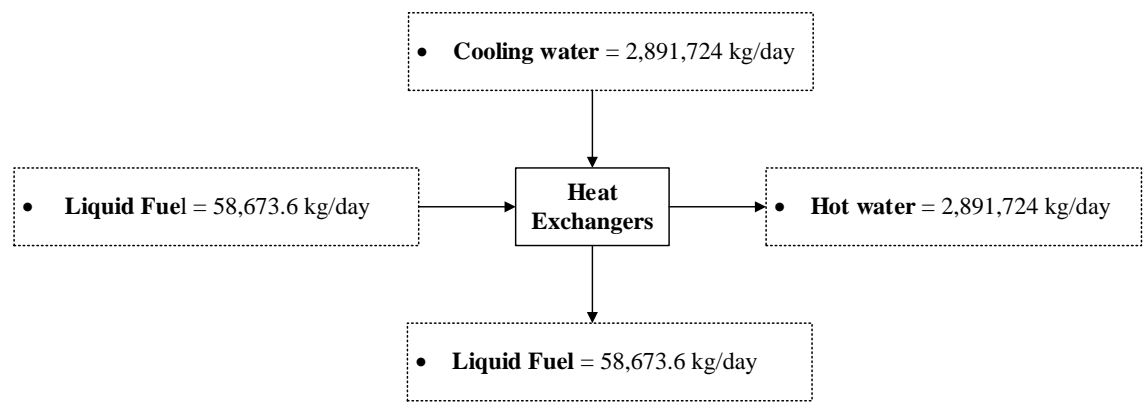

Figure 16. Material balance on heat exchangers.

- $\quad$ LDPE $=13,964,252.6 \mathrm{~kJ} / \mathrm{day}$

- $\mathbf{H D P E}=23,430,565.6 \mathrm{~kJ} / \mathrm{day}$

- $\quad \mathbf{P P}=19,277,825.9 \mathrm{~kJ} / \mathrm{day}$

- $\quad$ PS $=9,423,586.0 \mathrm{~kJ} /$ day

Figure 17. Energy balance on extrusion.

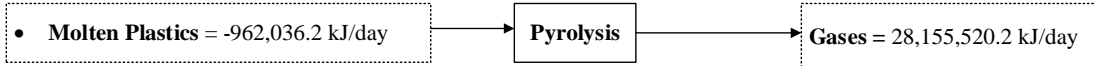

Figure 18. Energy balance on pyrolysis.

Gases $=28,058,219.3 \mathrm{~kJ} / \mathrm{d}$

Figure 19. Energy balance on catalytic cracking.

- Gases = -962,036.2 kJ/day

$\longrightarrow \quad \begin{aligned} & \text { Fractional } \\ & \text { Distillation }\end{aligned}$

Refinery Gases = -6,598,598.0 kJ/day

Gasoline $=-195,574,709.8 \mathrm{~kJ} /$ day

Kerosene $=-6,775,854.9 \mathrm{~kJ} /$ day

Diesel = -9,707,327.6 kJ/day

Residual $=-1,123,980.4 \mathrm{~kJ} /$ day

Figure 20. Energy balance on fractional distillation.

- $\quad$ Liquid Fuel $=41,837,612.1 \mathrm{~kJ} /$ day

- Cooling water $=10,117,193.0 \mathrm{~kJ} /$ day

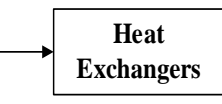

Liquid Fuel = 4,019,105.3 kJ/day

Figure 21. Energy balance on heat exchangers.

\subsection{Economic Analysis}

From the assessment of the various economic variables concerning the feasibility and profitability of this project, a total capital of $\$ 16,985,305$ invested into the project would yield an annual rate of return of $34 \%$. This ROR value is well within the range of businesses looking to make appreciable profits in Ghana since the current inter-bank interest rate is $15.22 \%$ [12]. The project is therefore economically feasible for the 25 -year period of the plant's operation. Also, the time that would be required to pay back the initial investment is approximately 3 years from start of production, as can be seen from Figure 22 below. This duration is financially healthy and falls within the optimum payback period for chemical plants to pay off their initial investment and break even. 


\section{A graph of cumulative cash flow against plant life}

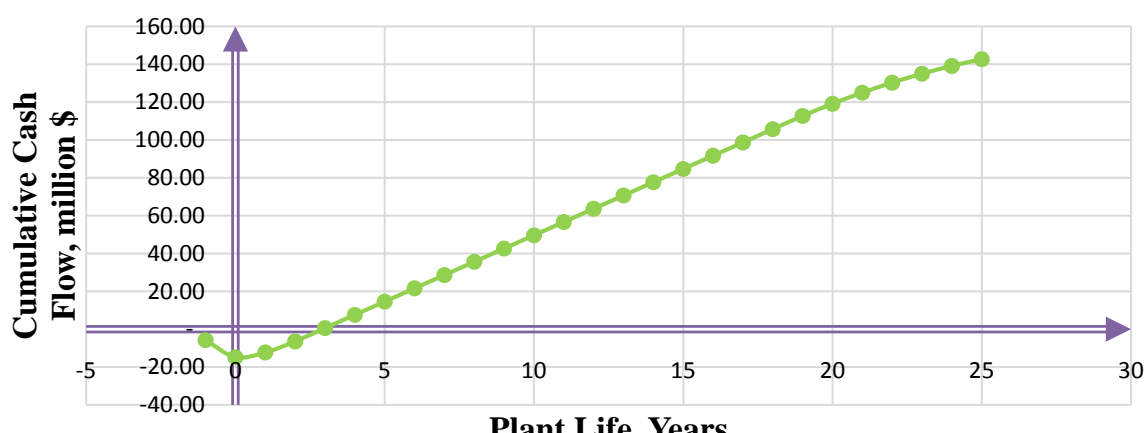

Plant Life, Years

Figure 22. Cummulative cash flow curve.

The sensitivity analysis on the project proved that upon the 16 cases considered there were two instances which varied significantly with respect to the pay-back period at normal conditions. One is $10 \%$ decrease in annual sales while raw material cost remained the same and the other is $10 \%$ decrease in annual sales and raw materials cost. This indicates that, when the plant is in operation for some years and the cost of raw materials and annual sales vary by $5 \%$ or $10 \%$ except for the two cases described above, the company will suffer no loss in paying off its initial investment and breaking even. This makes this project a viable one to an investor.

\subsection{Safety Consideration and Plant Location}

Any chemical industry is obliged morally and legally to safeguard the health and well-being of its employees, the general public and the environment. Operating under safe working environment is also good business. Moreover, the good management practices needed to attain safe operation will also ensure efficient operation [11].

Safety measures such as effective communication of hazards and safety protocols, strategies for accident prevention, obeying rules on the material safety and data sheet of the catalysts and the liquid fuels in the plant were all considered in designing this plant. To this end, the various equipments would be tested and maintained regularly to prevent them from deteriorating. Storage tanks containing fuels would be coated with a heat reflecting agent to minimize external heating. Level, temperature and pressure control devices are mounted on process units to keep all process variables with design specifications. All tanks containing flammable liquids would be clearly labelled and adequate firefighting substances would be installed.

With respect to pollution prevention and control, stacks were specified at heights of $70 \mathrm{~m}$. At such heights, the flue gas containing primarily $\mathrm{CO}_{2}$ and sometimes $\mathrm{CO}$ disperse in a large area so that their ground level concentrations are within permissible levels not harmful to the environment [13]. The wastewater from the plant would be pumped to a quiescent stabilizing pond for monitoring before 
discharge to ensure it meet the Environmental Protection Agency (EPA)-Ghana guidelines. The guidelines regulating the maximum permissible level before discharge are $\mathrm{pH}(6-9), \mathrm{COD}(<250 \mathrm{mg} / \mathrm{L})$, Total Dissolved Solids $(<1000 \mathrm{mg} / \mathrm{L})$, Total Suspended Solids $(<50 \mathrm{mg} / \mathrm{L})$, Sulphate $(<250 \mathrm{mg} / \mathrm{L})$ Conductivity $(750$ $\mu \mathrm{S} / \mathrm{cm}$ ), Turbidity (75 NTU) [14].

The suitable location for the plant is Kpone near Tema-Accra in Ghana. Plastic waste, the main raw material can be sourced from the Kpone landfill, Kpone. The factors that favoured the siting of the plant were nearness of plant to source of raw materials, closeness to the product's market, availability of transportation networks, easy access to utility and labour supply-a greater proximity to other industries can be a good factor as recruitment of persons with necessary skills sets becomes relatively easy from such a large pool of human resource [11]. Kpone is within the Tema free zone region. The conditions at the chosen location meet the safety and environmental requirements and Ghana Government's industrial policy. Hence, production and distribution will be cost-effective and feasible in Kpone.

\section{Conclusion and Recommendation}

From the economic analysis, the plant for conversion of waste plastics into fuel is economically viable. The technology needed to operate this plant is also available. The plant will not pose any environmental threats. The main feedstock needed is in abundance at the Kpone landfill site. The products of the plant have a ready market locally and in neighboring countries. Plastics are non-biodegradable materials that may cause environmental pollution when disposed haphazardly to the environment. However, this technology protects the environment by converting plastics to commercial-grade fuels. In the face of the energy transition taking place globally, it would be expedient to recycle the plastic waste fraction of MSW into clean useful fuel. Given the techno-economic viability of such a plant, it can therefore be recommended that a feasibility study can be pursued to advance the realisation of using a plastic pyrolysis plant to produce commercial-grade fuel.

\section{Acknowledgements}

The authors hereby acknowledge persons from the 2019 Graduating Class of Chemical Engineering who took part in the design project. These are Ayi Charles Kofi, Appiah-Kubi Millicent, Asante Raymond, Boadi Rachael, Asiedua-Ahenkorah Lois and Owiredu Alfred.

\section{Conflicts of Interest}

The authors declare no conflicts of interest regarding the publication of this paper.

\section{References}

[1] Sharma, P.V. and Singh, P. (2015) Integrated Plastic Waste Management: Environmental and Improved Health Approaches. Procedia Environmental Sciences, 35 
692-700. https://doi.org/10.1016/j.proenv.2016.07.068

[2] Blanco, I., Loisi, R.V., Schettini, E., Sica, C. and Vox, G. (2018) Agricultural plastic waste mapping using GIS-A case study in Italy. Resources, Conservation and Recycling, 137, 229-242. https://doi.org/10.1016/j.resconrec.2018.06.008

[3] Snigdha, C. (2003) Economics of Solid Waste Management: A Survey of Existing Literature.

https://www.researchgate.net/publication/285232859_Economics_of_Solid_Waste Management_A_Survey_of_Existing_Literature

[4] Teye, R.N. (2012) Plastic Waste Management in Accra. Degree Thesis, Acarda University of Applied Science, Acard.

[5] Arena, U. (2012) Process and Technological Aspects of Municipal Solid Waste Gasification Review. Waste Management, 32, 625-639.

https://doi.org/10.1016/j.wasman.2011.09.025

[6] Gheewala and Liamsanguan (2008) Incineration and Landfilling. https://sites.google.com/a/owu.edu/ecology-project/home/incineration-and-landfilli $\underline{\mathrm{ng}}$

[7] UNEP (2009) Converting Plastic Waste into Resources: Compendium of Technologies Osaka.

https://wedocs.unep.org/bitstream/handle/20.500.11822/8638/WastePlasticsEST_Co mpendium_full.pdf? sequence $=3$ \&isAllowed $=\mathrm{y}$

[8] Mani, M., Nagarajan, G. and Sampath, S. (2011) Characterisation and Effect of Using Waste Plastic Oil and Diesel Fuel Blends in Compression Ignition Engine. Energy, 36, 212-219. https://doi.org/10.1016/j.energy.2010.10.049

[9] Ajo, I.J., Anand, S., Amal, J., Cighil, T. and Sildarth, J. (2017) Waste Management by Pyrolysis. International Journal of Advanced Research in Engineering and Management, 3, 60-64.

https://1library.net/document/q51x4k3y-waste-management-by-pyrolysis.html?utm _source=related_list

[10] Sinnott, R.K. (2005) Coulson \& Richardson's Chemical Engineering Design. Elsevier Coulson \& Richardson's Chemical Engineering Series, 6, 231, 477.

[11] Sinnot, R.K. (2013) Coulson and Richardson Chemical Engineering Design. 3rd Edition, Butterworth Heinemann, London, 794-848.

[12] Bank of Ghana (2019) Monthly Interest Rates. https://www.bog.gov.gh/economic-data/interest-rates/

[13] Daniel, A.C. and Joseph, F.L. (2011) Chemical Process Safety: Fundamentals with Applications. 3rd Edition, Prentice Hall, Boston, United States.

[14] Agyemang, E.O., Awuah, E., Darkwah, L., Arthur, R. and Osei, G. (2013) Water Quality Assessment of a Wastewater Treatment Plant in a Ghanaian Beverage Industry. International Journal of Water Resources and Environmental Engineering, 5, 272-279. 